\title{
Jokes, aporia and undecidability
}

\author{
Alex Segal \\ European Charles Sturt University \\ asegal@csu.edu.au
}

\begin{abstract}
Derrida saw laughter as a version of aporia; and he linked aporia to an undecidability that he ties to fiction. I argue that such undecidability contributes to some jokes. Sometimes this undecidability enables the joke to combine plausibility and delightfulness. More interesting and more aporetic is the way that undecidability contributes to jokes that foreground their textual status (some meta-jokes for instance) and those that have an effect of unfathomability. The jokes considered include one on which Derrida commented and another which was told at his Columbia University memorial service.
\end{abstract}

Keywords: jokes, undecidability, aporia, fiction .

\section{Introduction}

Benoit Peeters, in his biography, speaks of Derrida's love for funny stories, especially Jewish jokes; and he cites Samuel Weber saying that to Derrida laughter was "another version of aporia" (Peeters \& Brown 2013; Kindle Location 9156). My main focus here is on the question of whether a kind of undecidability that Derrida links to aporia and in terms of which he expresses his passion for literary fiction is relevant to humour-to jokes in particular. At issue is fiction's potential to generate a multiplicity of hypotheses - a multiplicity of imaginary worlds. The narrator of Baudelaire's La fausse monnaie ('Counterfeit Money') accepts at face value his friend's claim that he (the friend) gave a counterfeit coin to a beggar. But Derrida argues that the reader can hypothesise that the friend ('a connoisseur of counterfeit money, that is, ... a liar') 'gave real money and then boasted ... that he gave a "counterfeit coin", (Derrida 1992: 150); and that it is senseless for the reader to wonder "what actually happened, what was the true intention of the narrator's friend' (Derrida 1992: 153). So what actually happened in the fictional world is undecidable. The reader can oscillate between seeing a character in this world as telling the truth and seeing this character as lying. Possibly a better way of describing this would be to say that the work generates more than one fictional world, and that it is not possible to privilege one of these fictional worlds over the other. It is on this type of undecidability that my discussion will focus.

Humour is often characterised in terms of oscillation. Niall Shanks and Hugh LaFollette explain the humour in the newspaper headline, 'Obscene Performance: Magistrates to Act' in 
terms of our oscillating 'between viewing magistrates as performing obscene acts and viewing them as halting such acts' (Shanks \& LaFollette 1993: 330); in the case of a tearful child who when asked why he had kicked his sister in the stomach replied: 'I didn't mean to kick her in the stomach. I meant to kick her in the head but she moved', the oscillation is 'between seeing a child sorry for hurting his sister and a child sorry for missing his target' (Shanks \& LaFollette 1993: 333). But given neither the headline nor the tearful utterance is a fiction, at issue here is not the undecidability that Derrida ties to fiction. Moreover, the oscillation in this kind of undecidability is not funny in the way that the oscillations that Shanks and LaFollette refer to are funny. So this kind of undecidability is clearly not essential to humour. Whether it is sometimes relevant to humour, to jokes in particular, is what I consider in this paper. But first I briefly connect jokes and aporia more generally-aporia that is not a matter of the undecidability that Derrida ties to fiction. I begin with a joke that Derrida discusses.

\section{A couple of jokes that Derrida loved}

Two Jews, longstanding enemies, meet at the synagogue on the day of the Great Atonement. One says to the other [by way of forgiveness] 'I wish you what you wish me.' And the other replies, giving tit for tat: 'See, you're doing it again!'

(Derrida, Brault, \& Naas 2001: 184)

Derrida comments:

... two enemies make the gesture to forgive one another, they feign to do so, 'for laughs,' but by inwardly reopening or pursuing the hostilities. In this process, they admit to this inexpiable war, and blame one another for it reciprocally, as if in a mirror.

... what these two Jews come to experience and what makes us laugh is indeed the radical impossibility of forgiveness.

... To admit to, to share, to entrust to one another this insurmountable test of the unforgivable, to deem oneself unforgivable for not forgiving, is perhaps not to forgive ... but it is to sympathise with the other in the test of the impossible.

Here it is, then - the ultimate compassion.

It is to tell the other, or to hear oneself tell the other, and to hear the other tell you: you see, you're doing it again, you don't want to forgive me, even on the day of the Great Atonement, but me too, me neither ... we're in agreement, we forgive ourselves for nothing, for that's impossible, so let's not forgive one another, all right? And then you burst into complicitous, uncontrollable laughter, laughing like crazy, with a laughter gone crazy. For isn't this paradoxical agreement peace? Yes, that's peace, that's life: that, in the end, is the great atonement. And what is more comical than the great atonement or forgiveness as the test of the unforgivable? What could be more alive, what better reconciliation could there be? What an art of living!

(Derrida et al. 2001: 185-186)

Inasmuch as the Great Atonement is the test of the unforgivable, inasmuch as not forgiving is tied to compassion, there is aporia. And grasping this aporia generates laughter-Derrida's laughter and, on Derrida's interpretation of the joke, the laughter of the characters in the joke. Aporia also marks a joke which was told at his 2004 Columbia University memorial service:

On Yom Kippur, the rabbi stops in the middle of the service, prostrates himself beside the bema, and cries out, 'Oh, God. Before You, I am nothing!' Saul Rosenberg, president of the temple is so moved by this demonstration of piety that he immediately throws himself to the floor beside the rabbi and cries, 'Oh, God! Before you, I am nothing!' Then Chaim Pitkin, a tailor, jumps from his seat, prostrates himself in the aisle and cries, 'Oh God! Before You, I am nothing!' Rosenberg nudges the rabbi and whispers, 'So look who thinks he's nothing' 
Mary-Jane Rubenstein relates this version of the joke to a profound paradox articulated by the theologian Pseudo-Dionysius: 'the soul must prove itself worthy of realizing it is nothing. Not just anybody can know nothing, and not just anybody can become nobody' (Rubenstein 2008: 738). This paradox is more evident in a version of the joke in which a great cantor and a great rabbi are self-deprecating in response to praise. The one says 'his singing wasn't bad, but when he thinks of the great cantors of the past, he is really nothing', the other that his sermon 'was not bad, but when he thinks of the great rabbis and great sermons of the past, he is really nothing'. When, echoing this talk, the shammas, the sexton in the synagogue, says, 'The synagogue was prepared all right, but when I think of the great shammases of the past, I'm really nothing', the rabbi and the cantor 'turn to each other and say, "Look who says he's nothing!" ' (Berger 2010: 113). Asa Berger sees elitism here: 'the lowest person in the social order' (Berger 2010: 113) is not entitled to the 'false modesty' earned by the others; but Berger notes that these others are 'really vain' and 'only pretending to be modest' (Berger 2010: 114). Emphasising Derrida's anti-hierarchicalism and the way that it punctures the attitude of the punchline speaker, Rubenstein sees in the version of the joke she cites a deconstruction of the Dionysian idea that not just anybody can become nobody: if 'the order of things is a creative disorder' and 'the lowest is most highly reflective of God', then the theoethic of Dionysius 'unsettles the very hierarchy and teleology it posits' (Rubenstein 2008: 738). More obviously anti-hierarchical is the version cited by Žižek (who tells us that the joke was 'loved by Derrida'):

First, a rabbi stands up and says: 'O God, I know I am worthless. I am nothing!' After he has finished, a rich businessman stands up and says, beating himself on the chest: 'O God, I am also worthless, obsessed with material wealth. I am nothing!' After this spectacle, a poor ordinary Jew also stands up and also proclaims: 'O God, I am nothing.' The rich businessman kicks the rabbi and whispers in his ear with scorn: 'What insolence! Who is that guy who dares to claim that he is nothing too!'

(Žižek \& Mortensen 2014: 52)

The hot-under-the-collar businessman perhaps thinks that the nullity claim displays modesty only if made by someone of standing (like himself); otherwise it risks undermining this ethical value and the recognition of the standing. Ridiculously, he is annoyed by the undermining both of his self-effacement and of the recognition, which he thinks owed to him, of his standing and even of his self-effacement, a recognition that annuls self-effacement. And he has no redress for the perceived slight. For the non-entity can truthfully say he is nothing.

Although often ridiculous, this paradoxical interplay of self-effacement and self-assertion is common, and difficult to avoid. Certainly it is often noted-for example, by the Jewish saying 'Too much modesty is half-conceit', and by Sir Philip Sidney's mockery of moral philosophers: 'rudely clothed, for to witness outwardly their contempt of outward things, with books in their hands against glory, whereto they set their names' (Sidney 2002: 88). Derrida is particularly responsive to this kind of paradox. Contrasting the gift and the exchange, he argues that the gift, which involves giving oneself over to the other and a loss of self, is annulled if it earns gratitude or even recognition as gift. These returns reduce it to an exchange, giving back 'in the place, let us say, of the thing itself, a symbolic equivalent' (Derrida 1992: 13). Recognition annuls the gift even if it comes from the donor: the donor of the gift, Derrida argues, 'must not see it or know it either; otherwise he begins, at the threshold, as soon as he intends to give, to pay himself with a symbolic recognition' (Derrida 1992: 14). And this yields a kind of paradox: 'If the gift appears or signifies itself, if it exists or if it is presently as gift, as what it is, then it is not, it annuls itself' (Derrida 1992: 26-27). Derrida's paradox of the 
gift can be reworded so that it pertains to self-effacement and to nullity: 'If self-effacement appears or signifies itself, if it exists or if it is presently as self-effacement, as what it is, then it is not, it annuls itself'; 'If nullity appears or signifies itself, if it exists or if it is presently as nullity, as what it is, then it is not, it annuls itself'. In appearing or signifying itself, the selfeffacement of the businessman annuls itself - and hence we laugh at him. Though not a joke, Derrida's statement of the aporia of the gift might make us smile - but not at anyone, suggesting that the humour of the nullity joke extends beyond the individual.

Our tending to laugh with the punchline speaker of one version of the joke, at the speaker of another, is tied to each version having its own imaginary world. Let's now consider the possibility of a single version of a joke generating more than one imaginary world.

\section{Undecidability and jokes}

Such multiplicity is common. In fact, undecidability as to whether the punchline speaker is in on the joke is so common as perhaps to be uninteresting in the case of a particular joke; and given that jokes tend to be funny on either interpretation, and given the importance of immediacy, the dual perspective may seem inessential to and even a distraction from the joke. Nor is there a sense that those who craft jokes intend the dual perspective to be an aspect of the joke. But I think such undecidability warrants more attention than it has received. Let's consider some particular cases.

Hurley et al. suggest that the punchline of the following joke can be taken at face value or as a trick - and that we cannot know which it is (Hurley, Dennett, \& Adams 2011; Kindle Locations 2050-2051):

A man wakes up from his terrible hangover, and finds his wife has prepared a beautiful breakfast in bed for him. What has he done to deserve this? He came home stinking drunk, vomiting all over everything, after a night on the town. He was too far gone even to get himself into bed, and his angry wife had to half-carry him to the bedroom. When she tried to pull the puke-drenched clothes off his almost inert form, he yelled out 'Stop, bitch! Get your hands off me! I'm a married man!'

(Hurley et al. 2011 Kindle Locations 2047-2051)

Hurley et al. then downplay the undecidability: 'it's funny either way.' But if at issue in the joke is the naivety of the wife who, as they point out, never considers the possibility that her husband's utterance should be taken at anything other than 'face value,' then a sophisticated response to the joke's undecidability that keeps diverse hypotheses in play might contribute to the placement of this naivety; might resonate with the content of the joke, thus amounting to a richer response to the joke.

Debra Aarons suggests that in the following joke, Mary can be seen as behaving either 'ingenuously' or 'very cleverly':

The third grade teacher says, "Mary, I'd like you to give me a sentence beginning with "I", please.' Mary hesitates for a few seconds then says, 'I is ...' The teacher interrupts her, 'No Mary, you cannot begin a sentence with "I is"-you must use "I am".' Mary appears upset and tries to protest, 'But Teacher...' The teacher insists, 'I asked you to give me a sentence beginning with "I", and use "am", please.' Mary shrugs, 'I am the ninth letter of the alphabet'.

(Aarons 2012: 203)

Aarons mentions the dual perspective merely in passing as it were, perhaps downplaying its importance. But I think that as each hypothesis is funny in a different way, positing both might enrich the joke. Moreover, the uncertainty at issue - unknowability about how much a pupil knows: is the third-grader naive or very smart?-might contribute to the teacher's 
discomfiture; and hence it might contribute to the joke's debunking of authority figures in institutions that impart knowledge. And it might serve the kind of function evoked by William Empson's comment that in The Beggar's Opera it is unknowable how much the characters have intended: 'The puppets are plausible if they don't mean all that the play puts into their words and delightful if they do, and the shift between the two theories is so easy that we take them as both' (Empson 1938: 214-215). In jokes, plausibility, though often immaterial, sometimes (as with this joke) adds something. Although Mary is more likely to be very clever than is Mrs Peachum, it is more likely still that she is ingenuous. So the double perspective may work in the joke much as it does in the play, albeit to a lesser degree. And the ease that Empson speaks of suggests that the enrichment may not detract from immediacy - and in any case, appealing to immediacy may underestimate how rich and complex a joke can be. Perhaps because of this ease and perhaps because in this case the relationship of the two possible interpretations is not very rich, the undecidability here does not seem particularly aporetic.

More aporetic is the undecidability that marks another pedagogical, linguistic joke:

'Why should "eretz" be spelled with a gimmel?'

'A gimmel? It isn't.'

'Why shouldn't "eretz" be spelled with a gimmel?'

'Why should "eretz" be spelled with a gimmel?'

'That's what I'm asking you-Why should "eretz" be spelled with a gimmel?'

(Aarons 2012: 202)

Aarons sees here a punchline speaker who wins a "one-upmanship battle" (Aarons 2012: 202) - who (in effect) knows that the only motivation for asking his first question is as part of such a battle. But Ted Cohen imagines someone who loses his bearings as a result of being consumed by the Jewish tradition of study in which one 'argues, debates, contests, criticizes, and learns; and ... does not stop' (Cohen 1999: 66). At issue in the joke is the way that the reasonableness of a question depends on context. Asked in response to someone saying 'Why shouldn't "eretz" be spelled with a gimmel?', the question 'Why should "eretz" be spelled with a gimmel?' is reasonable; but not if asked out of the blue. So if the undecidability about the punchline speaker pertains to his motivations in asking this question (a matter of the context of the question), it doubles the most obvious subject matter of the joke- a subject matter which is already about a kind of ambiguity. And the sense of losing one's bearings is doubled if it is undecidable whether or not the punchline speaker has lost his bearings. So here the undecidability is aporetic.

It may be so too in another joke where the punchline speaker can be seen as either ingenuous or clever. The setting this time is medical rather than pedagogical.

A man goes to see a psychiatrist. The doctor asks him, 'What seems to be the problem?' The patient says, 'Doc, no one believes anything I say.' The doctor replies, 'You're kidding!'

(Oring 2003: 1)

The (relatively) ingenuous doctor expresses his genuine surprise about the disbelief that the patient reports, using a phrase ('You're kidding!') which, taken literally, incongruously expresses the very disbelief about which the doctor expresses surprise - an incongruity which he misses. ${ }^{1}$ The clever doctor, grasping the gulf between the literal meaning of the phrase and what it is generally used to express, uses the phrase jokingly-perhaps in order to put the patient at ease. As with the other jokes we have considered, each interpretation is funny-and in different ways, so both contribute to the joke. Here the clever interpretation, although a little less plausible than the ingenuous, seems plausible enough to me. So the shift between interpretations may not combine plausibility and delightfulness. But it may (and this is similar) 
combine immediacy (which pertains to the ingenuous interpretation) and multi-layeredness (which pertains to the clever interpretation). On the clever interpretation, the joke in a sense becomes a joke about a joke. Given the synonymy of 'kidding' and 'joking', the punchline describes what its utterer himself is doing-and also what the teller of the fictional joke is doing. The speaker seems to cite rather than use directly the phrase 'You're kidding!', perhaps pretending to say it as it is said by someone who expresses concerned surprise. So in picturing the psychiatrist as himself joking, we may also imagine the kind of psychiatrist who speaks seriously (and more naively).

Aporetic undecidability seems to pertain to a joke that foregrounds uncertainty:

Two Jews have come to a rabbi to settle a legal dispute. Two dignified Jews with beard and earlocks, just as required. As usual, the rabbi's wife is also seated in the room. The rabbi says to one of the Jews: 'So, what's your complaint?' He answers that the story is such and such, and he has to pay and he has to do this and he has to do that; in short, he gives such a fine account and argues his case so clearly that the rabbi has to say: 'You're right.' The rabbi then addresses the second Jew: 'And what do you have to say?' The second Jew is nobody's fool either, and he also has a mouth to defend himself with; he argues his case so clearly that there is nothing left to be said, and that he owes nothing — not one cent. The rabbi says to him: 'You're right.' The rabbi's wife has never heard the likes of this and says to her husband: 'You should live and be well! How can both of them be right? When one wins, the other has to lose.' The rabbi says to his wife: 'You're right, too'

(Raskin 2015: 13)

In a famous commentary, Richard Raskin affirms three views of this rabbi: 'a bungling incompetent, with no real understanding of the situation'; 'a very shrewd tactician who knows exactly what he is doing and why'; a wise man who recognises that 'reality is multi-facetted and internally contradictory in its very fabric' (Raskin 2015: 18, 19, 20). He associates such interpretive multiplicity with Jewish jokes; and with a kind of visual aporia that is found in the work of Escher - the impossible figure, a two-dimensional picture that appears to represent a three-dimensional reality which is in fact impossible. And he thinks that this multiplicity enriches jokes, albeit he is aware that the joke is funny on any one of the simple interpretations.

Raskin's multiplicity is not tied to fictionality. For if reality itself is multi-facetted, then multiple, even contradictory interpretations could apply to a single rabbi, who could be mindful both of the contradictoriness of reality (and so speak sincerely) and of tactics (and so be unconcerned about sincerity). And Raskin's account may require that one and the same action generate diverse judgments. Nevertheless, even if it is good to hypothesise a single multi-facetted rabbi, it may also be good to entertain three other hypotheses, each with a simpler rabbi than the multi-facetted one. For, in the context of this joke, not only do a rabbi who is just a fool and a rabbi who is just a sage each elicit humour in different ways, but a rabbi who is both fool and sage elicits humour in a different way again.

In entertaining the three simple hypotheses, at issue is a fictionality and an undecidability that yields an oscillation between sincerity and insincerity, insight and blindness, the humorous and non-humorous. ${ }^{2}$ The merely incompetent rabbi, blind to the inconsistency, is sincere; the tactician is unconcerned about truth; the sage is perhaps sincere but also playful, grasping the contradictoriness and the humour. His point of view might converge with that of the teller of the joke.

There is also doubling - not explored by Raskin - in the fact that the rabbi's judgment represented in the joke needs to be judged by the joke's interpreter, who tries to decide whether the rabbi is right to describe as right two statements which contradict each other and to describe as right a statement to the effect that he was wrong to describe as right both the contradictory statements. In trying to judge these matters, the interpreter might herself display 
bungling incompetence or shrewd practicality or wisdom or a blending of all three. But for the interpreter (in contrast to the rabbi), the content of the legal dispute is unknowable, secretindeed, absolutely unknowable, the joke being a fiction. It would be possible to argue that what the rabbi has to decide upon is in principle decidable - even if the correct answer is that both the disputants and the rabbi's wife are right_-but that what the audience of the joke is inclined to want to decide upon (whether the rabbi is right) is in principle undecidable. And this adds another level of aporia to that which Raskin has already identified.

Although the jokes we have so far considered allow for the possibility of the punchline speaker as a joker, they probably do not fit the category of meta-joke. And meta-jokes (or some of them) may have a special relationship to undecidability. Consider the following:

A priest, a rabbi, and a minister walk into a bar. The bartender looks up and says, 'Hey, what is this - some kind of joke?'

(Kelley 2016: 205)

Greg Kelley sketches at least two interpretations. On one, the bartender speaks idiomatically:

As an idiom in everyday parlance, the question 'What is this, some kind of joke?' is an expression of incredulity, and the referent has nothing to do with verbal jokes per se, but with actual lived situations. It appears plausibly that way as part of the fictive frame: we might well imagine a reallife bartender saying something similar were a real-life priest, rabbi, and minister to walk together into his bar.

(Kelley 2016: 206)

Unbeknownst to himself the bartender's words describe his situation (as this situation appears to the audience of the joke). Although he does not use the term 'joke' to describe the situation he is in, and may see nothing joke-like in the situation, for the audience of the joke the bartender is a character in a joke, in a situation we associate with a classic joke.

On another of Kelley's interpretations, the bartender uses the expression unidiomatically, albeit more literally, with the term 'joke' referring to a verbal joke or at least evoking the idea of a verbal joke. I think that a real-life bartender could do this in order, in a humorous vein, to register the way that here life imitates a fiction, imitates a joke. Part of his humour could reside in the playfulness of his knowingly using the expression unidiomatically. And beyond the bartender's humour, is the humour in the fact that from our point of view, a character (the bartender) who sees his situation as merely joke-like is a character in an actual joke. In contrast to the interpretation I have just offered, Kelley himself seems to see here not an imaginary real-life bartender but a fourth-wall breaker who knows he is a fictional character and who hence could not be a real-life bartender; a character who puts paid to realism:

It is indeed some kind of joke, but we don't expect that observation to come from an imagined character within the text. ... the bartender's this refers to the fiction in which he as a character exists. So he is literally-self-consciously_aware of himself and the others as participants in the action.

(Kelley 2016: 205-206)

Kelley's hypothesis, unlike the other two, stretches the idea of an imaginary world to breaking point. On any of these interpretations, the joke is funny-so keeping more than one in mind is not essential to the joke. But given the textual self-consciousness of the humour here, a diversity of interpretations seems more intrinsic to this joke than to those considered earlier. Here is another meta-joke that Kelley cites: 
A priest, a rabbi, and a minister are sitting together on a plane. The rabbi looks at the other two and asks, 'Say, did you hear the one about us?'

(Kelley 2016: 212-213)

I think we are likely to see this punchline speaker as in on the joke-clever rather than ingenuous. But his utterance invites more than one interpretation. On one hypothesis, he is cracking a joke of the kind that consists of a witty one-liner, a stand-alone wry comment - in which case he is not using the sentence idiomatically, not using it to introduce a joke. There is humour (both for those within the world of the joke and for the audience outside the fiction) in the fact that a witty one-liner, a joke in itself, takes the form of the kind of sentence that introduces a joke. And for the audience outside the fiction, some of the humour lies also in the fact that this punchline (sometimes categorized as the third part of a joke) consists of the kind of sentence that is used in the framing of a joke (categorized as the first part of the joke). On another hypothesis, the punchline speaker is using the sentence idiomatically, to introduce a joke - albeit a joke that never reaches its punchline. Kelley describes a conceivable scenario which in a sense borders on being inconceivable:

Cognizant that he inhabits 'the one about us,' the rabbi heralds another anticipated joke performance, and we might guess where things could go from there. If the rabbi were to relate this very joke, which itself frames the beginning of another telling, it conceivably could stand as the inaugural link in a perpetual chain of jokes within jokes, a comic self-referential mise en abyme. ${ }^{3}$

(Kelley 2016: 213)

If this mise en abyme is comic, then so too might be an undecidability about which of the two hypotheses to affirm. On any of the hypotheses, this is a joke that plays with the form of a joke; and such play is multiplied if we oscillate between the hypotheses; amongst other things, the undecidability concerns whether or not there is a single iteration of the punchline. And if the audience might speculate about a perpetual chain of jokes within jokes, then so might it speculate about multiple hypotheses: mise en abyme and undecidability, features that might seem to undermine the immediacy of the joke, contribute I think to a sense that the textual surface of the joke cannot be subordinated to a unified meaning; contribute to the playfulness of the joke-playfulness tied to humour.

Being obviously fictional, narrative jokes have been my focus. Yet even a one-liner-a non-narrative joke - can create the impression of fictionality, the impression of being an utterance of an imaginary character, perhaps even of more than one. Although comedian Mitch Hedberg's 'All these jokes have been pre-approved as funny by me' is obviously an utterance of a real person, we perhaps imagine it being said not as a joke but seriously as the utterance of an imaginary character who uses the phrase 'All these jokes' to refer to utterances other than the current one, which he does not think of as a joke. And we can also perhaps picture it as uttered by another imaginary character who intends this phrase to include the joke he is currently uttering but who is unaware of the impossible figure thereby generated. Both interpretations are funny; there is humour in the mere idea of jokes being quality-assured, and in the idea that such quality assurance involves the authority of an expert. And on the first interpretation, there is humour in the fact that the speaker does not think his utterance is a joke. On the second interpretation, the joke becomes madcap, doubling over on itself as it were, involving mise en abyme, breaking with plausibility and stretching the idea of an imaginary world to the limit. The vertiginous second interpretation is already aporetic. But further aporia arises from the oscillation between interpretations - an oscillation that displaces the border between the inside and the outside of the joke. So here is another joke to which undecidability seems intrinsic. I think Derrida would have loved it. 


\section{Undecidability and a couple of jokes loved by Derrida}

Compared to the meta-jokes, the jokes we earlier associated with Derrida are less selfconscious, less inclined to foreground their textual status. Nevertheless undecidability makes some contribution to them. In the nullity joke (Žižek's version) is the poor ordinary Jew ingenuous or clever? Does he speak in simplicity and humility - religiously? Or, grasping the incongruity of the situation and his utterance's likely effect, in order to debunk the businessman? Both interpretations being plausible, the shift here does not combine plausibility and delightfulness. It perhaps contributes to the force of the debunking - to our sense of the paradox in which the businessman is caught. If ingenuous, the debunking might be all the more provoking. If clever, then we laugh with the poor Jew, a jokester himself, who, in the world imagined by the joke, shares the spirit of the narrated joke. Perhaps also the oscillation resonates with the joke's interrogation of the status of a nobody. The ingenuous poor Jew, more than the clever poor Jew, is the kind of nobody that some might say has no right to say he is a nobody; but precisely for this reason he may be all the more 'reflective of God'. And the oscillation between the spontaneity-such as it is - of the ingenuous poor Jew and the calculation of the clever poor Jew resonates with the joke's explorations of the paradoxes of self-effacement.

And a little tweaking opens the punchline to diverse interpretations: 'The rich businessman whispers in the rabbi's ear: "Now one who really is nothing claims that he is nothing!" ' We might hypothesise that the businessman, blind to the incongruity that his words evoke, simply means to express scorn for the poor ordinary Jew (just as he did in Žižek's version of the joke); or alternatively, that, grasping this incongruity, the absurd aspect of his own conduct, he engages in wry self-mockery, debunks his hitherto earnest self-abasement; deprecates his self-deprecation-a nice twist on the self-deprecation which is often associated with Jewish humour. At issue is an oscillation around the idea of status - an idea central to what the joke is about.

This oscillation in interpretations - between the punchline betraying blindness (which we laugh at) and it expressing insight (which we laugh with) - contributes something to the joke; but less, I think, than to the legal dispute joke, which is about uncertainty; and less than to the meta-jokes with their endless textual play. Someone might try to argue, in Derridian mode, that the oscillation, involving as it does the radical unknowability of the intent of the speaker, displaces intention in a way that resonates with the joke's interrogation of self-effacement; that the radical unknowability, the radical unsayability, displaces the feature of jokes identified by Ted Cohen when he ties their concision to the way 'so much can go unsaid'. Unlike the unsaid that Derrida emphasises, Cohen's unsaid is not radical. For it is what 'the audience already knows' and tied to the mutual sense that teller and hearer 'are joined in feeling' (Cohen 1999: 25). I do not rule out this kind of speculation but I think it risks overburdening the joke.

Such speculation may be more pertinent to the Great Atonement joke-for Derrida an 'unfathomable story, a story that seems to stop in its tracks, whose movement consists in interrupting itself, in paralysing itself in order to refuse any future, an absolute story of the unsolvable, a vertiginous depthlessness, an irresistible whirlwind that draws forgiveness, the gift, and the giving back of forgiveness right to the abyss of the impossible' (Derrida et al. 2001: 184). Perhaps because of how much he is able to unpack from a single hypothesis, from a single imaginary world, he feels no need to entertain another. But other hypotheses are possible. Derrida sees the first Jew as feigning forgiveness - which fits with the second Jew giving tit-for-tat when he responds 'See, you're doing it again!' Although this may not rule out seeing the first Jew as both feigning forgiveness and being actually forgiving, Derrida does not consider the possibility that the first Jew seeks to be simply forgiving; and that the second, in ascribing hostility to him, either mistakes his attitude or deliberately misreads in order to 
debunk what he sees as a sentimental gesture, a debunking that would affirm the irreducibility of not forgiving. Here undecidability between hypotheses would seem to evoke a radical secrecy, a depthlessness that resonates with Derrida's sense that at issue is vertiginous depthlessness, paradoxical agreement, the unfathomable, the unsolvable, and a compassion that is tied to not forgiving. If unfathomability applies as it were to the world posited by a single hypothesis, by the most plausible of the possible hypotheses, then this unfathomability may be doubled by the unfathomability which is generated by a multiplicity of hypotheses. The aporia of undecidability supervenes on the aporia that is already at issue.

\section{Conclusion}

Undecidability pertaining to what happens in an imaginary world has received little attention in connection with jokes. Such undecidability may be less significant here than in literary fictions. Unlike jokes, literary fictions often elicit our interest in what happens in their imaginary worlds, ${ }^{4}$ and often evoke a sense of their characters' depth and inwardness, a sense which may dissolve with a realisation of the nothingness behind their literary phenomenon. Nevertheless, this undecidability does, on occasion, I have tried to suggest, contribute to jokes, perhaps most of all when it contributes to the aporia of the joke, even if it is not a necessary condition of such aporia

\section{Notes}

${ }^{1}$ Oring's suggestion that the audience ends up 'recognizing that the phrase identifies the psychiatrist as yet another disbeliever' (Oring 2003: 2) seems odd, given how rare it is to use 'You're kidding!' in a literal way.

${ }^{2}$ Perhaps another reason (related to the first) to see as relevant this undecidability about whether the rabbi intends humour, and about his intentions in general, is suggested by Scott Weems' notions that a joke involves the difference between 'expected and actual outcomes' and responding to a joke involves measuring 'distances between intended and unintended meanings' (Weems 2014: 41).

${ }^{3}$ Kelley is picturing the imaginary world of the joke as something like this:

A priest, a rabbi, and a minister are sitting together on a plane. The rabbi looks at the other two and asks, 'Say, did you hear the one about us? A priest, a rabbi, and a minister are sitting together on a plane. The rabbi looks at the other two and asks, "Say, did you hear the one about us? A priest, a rabbi, and a minister are sitting together on a plane. The rabbi looks at the other two and asks, 'Say, did you hear the one about us? A priest, a rabbi, and a minister are sitting together on a plane. The rabbi looks at the other two and asks, "Say, did you hear the one about us?", " and so on.

${ }^{4}$ Oring refers to our lack of interest in what happens in the case of jokes: 'the most generally inappropriate response that one can make to a joke is to ask, "And then what happened?" '; a 'joke is not a recounting of what happened to certain fictional characters' (Oring 2010: 86; 92). 


\section{References}

Aarons, D. (2012). Jokes and the Linguistic Mind. New York: Routledge. Berger, A. A. (2010). Blind Men and Elephants: Perspectives on Humour. New Brunswick: Transaction.

Cohen, T. (1999). Jokes: Philosophical Thoughts on Joking Matters. Chicago: University of Chicago Press.

Derrida, J. (1992). Given Time. I, Counterfeit Money (P. Kamuf, Trans.). Chicago: University of Chicago Press.

Derrida, J., Brault, P., \& Naas, M. (2001). The Work of Mourning. Chicago: University of Chicago Press.

Empson, W. (1938). English Pastoral Poetry. New York: W. W. Norton.

Hurley, M. M., Dennett, D. C., \& Adams, R. B. (2011). Inside Jokes: Using Humor to Reverse-Engineer the Mind. Cambridge, Massachusetts: The MIT Press.

Kelley, G. (2016). "The joke's on us": An analysis of metahumour', in M. D. T. Foster \& Jeffrey A. (eds), The Folkloresque: Reframing Folklore in a Popular Culture World, Logan: Utah State University Press, pp. 204-220.

Oring, E. (2003). Engaging Humour. Urbana: University of Illinois Press.

Oring, E. (2010). Jokes and their Relations. New Brunswick, N.J.: Transaction Publishers.

Peeters, B. and Brown, A. (2013). Derrida: A Biography (English ed.). Cambridge, UK ; Malden, MA: Polity Press.

Raskin, R. (2015). Life is like a Glass of Tea: Studies of Classic Jewish Jokes (Second ed.). New Orleans, Louisiana: Quid Pro Books.

Rubenstein, M.-J. (2008). 'Dionysius, Derrida, and the critique of "ontotheology" '. Modern Theology, 22(4), pp. 725-741.

Shanks, N. \& LaFollette, H. (1993). 'Belief and the basis of humor'. American Philosophical Quarterly, 30(4), 329-339.

Sidney, P. (2002). An Apology for Poetry (or the Defence of Poesy). Manchester: Manchester University Press.

Weems, S. (2014). Ha!: The Science of When We laugh and Why. New York: Basic Books.

Žižek, S. and Mortensen, A. (2014). Žižek's Jokes: (Did You Hear the One about Hegel and Negation?). Cambridge, Mass.: MIT Press. 